\title{
A Panic at the balneotherapy room - a case of gastric rupture after bag mask ventilation
}

\section{Background}

Bag mask ventilation is a safe and effective method frequently used. ${ }^{1}$ Most common complications associated with its use are recognized fairly quickly, although not always harmless. Despite the frequent occurrence of gastric distension there are few reports of massive gastric distension causing gastric rupture and pneumoperitoneum. ${ }^{2}$

\section{Case report}

50-year-old female patient, ASA 2, $2^{\text {nd }} / 3^{\text {rd }}$ degree burns in $34 \%$ of body surface caused by fire.

On the $22^{\text {nd }}$ day after admission she underwent balneotherapy.

Sedoanalgesia (midazolam + fentanyl + propofol + ketamine) Spontaneous ventilation, supplementary oxygen by nasal cannula
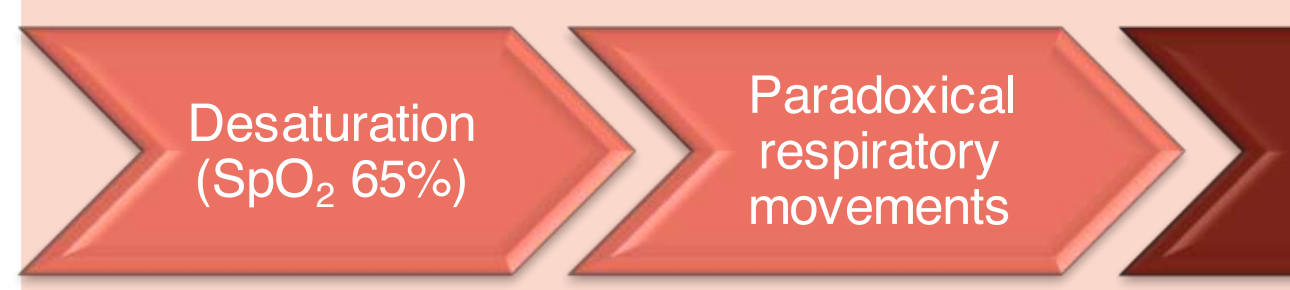

Bag mask ventilation $\mathrm{FiO}_{2} 100 \%$
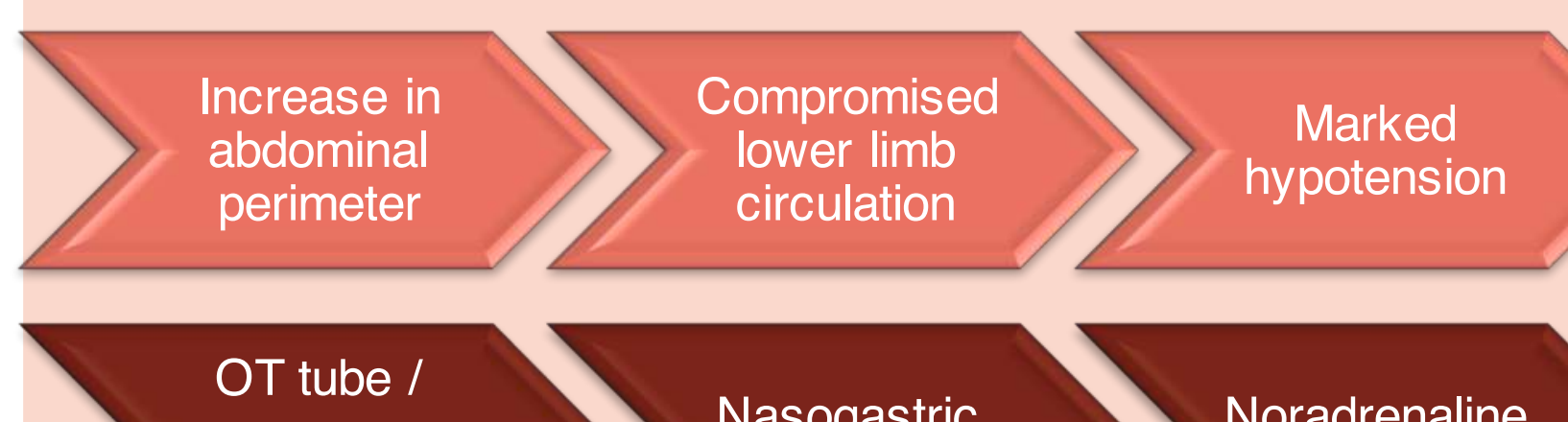

Mechanical ventilation
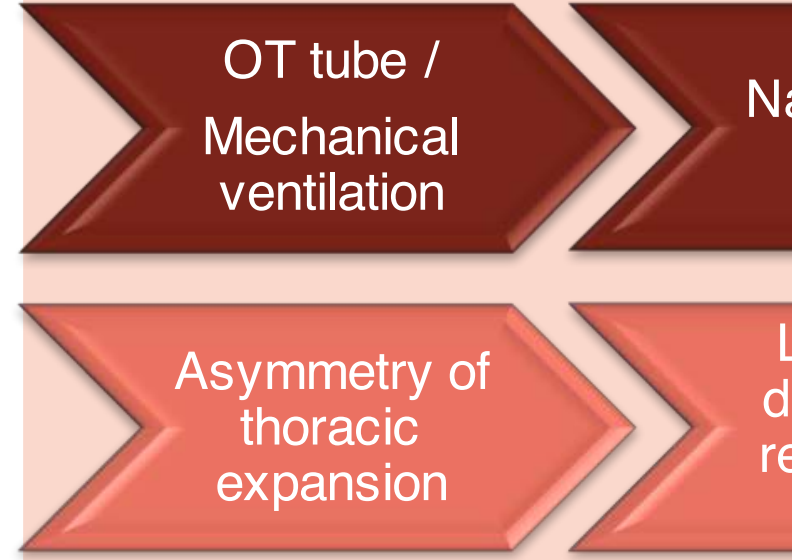

Nasogastric tube
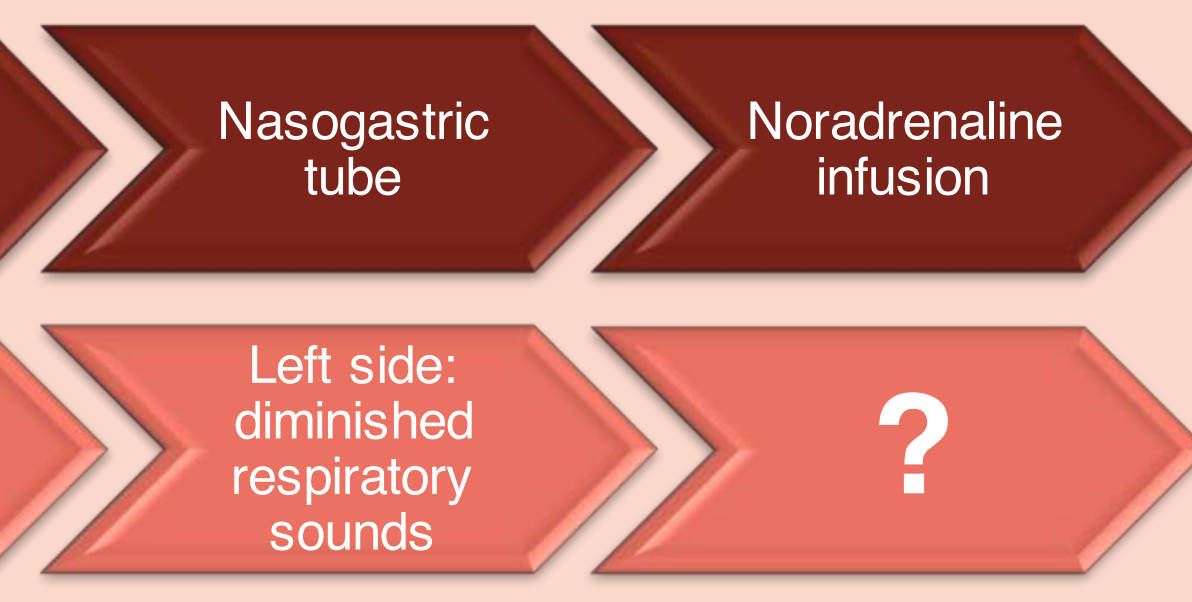

X-ray: left pulmonary atelectasis and pneumoperitoneum (images 1 and 2).

Emergent exploratory laparotomy: gastric laceration in an ischemic mucosa area.

The gastric laceration was surgically repaired. At the end of the procedure compartmental syndrome was resolved.

The patient was extubated on the $1^{\text {st }}$ postoperative day with no complications.

\section{Discussion}

Although bag mask ventilation is a routine practice, it is associated with several complications. Gastric rupture is a rare complication of this technique.

The higher incidence of Curling ulcers in burned patients could have contributed to gastric rupture and this case stresses the need to consider this potentially lethal complication.

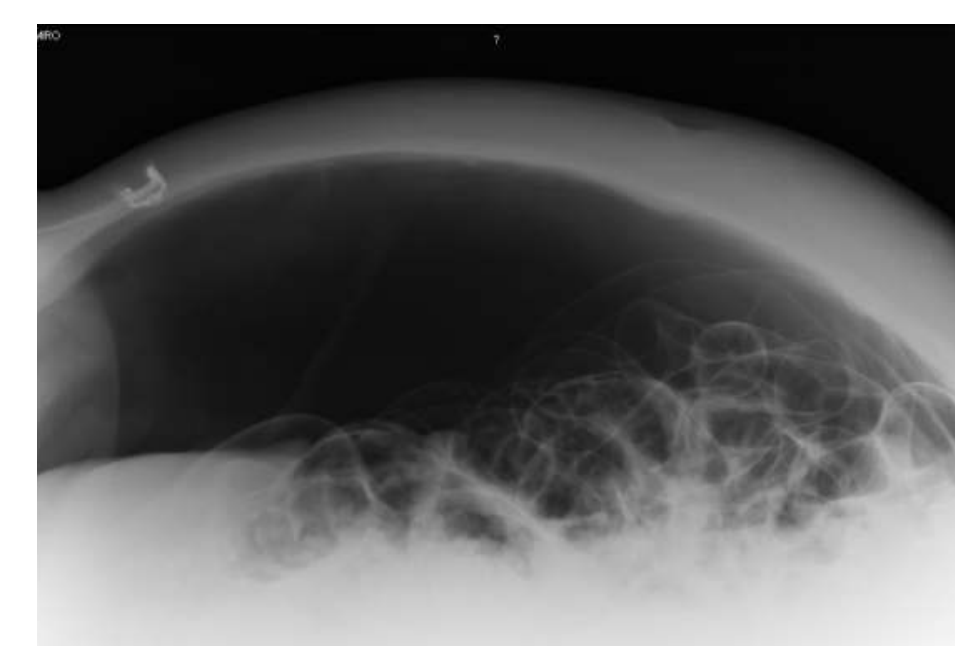

Image 1. Abdominal $x$-ray showing pneumoperitoneum.

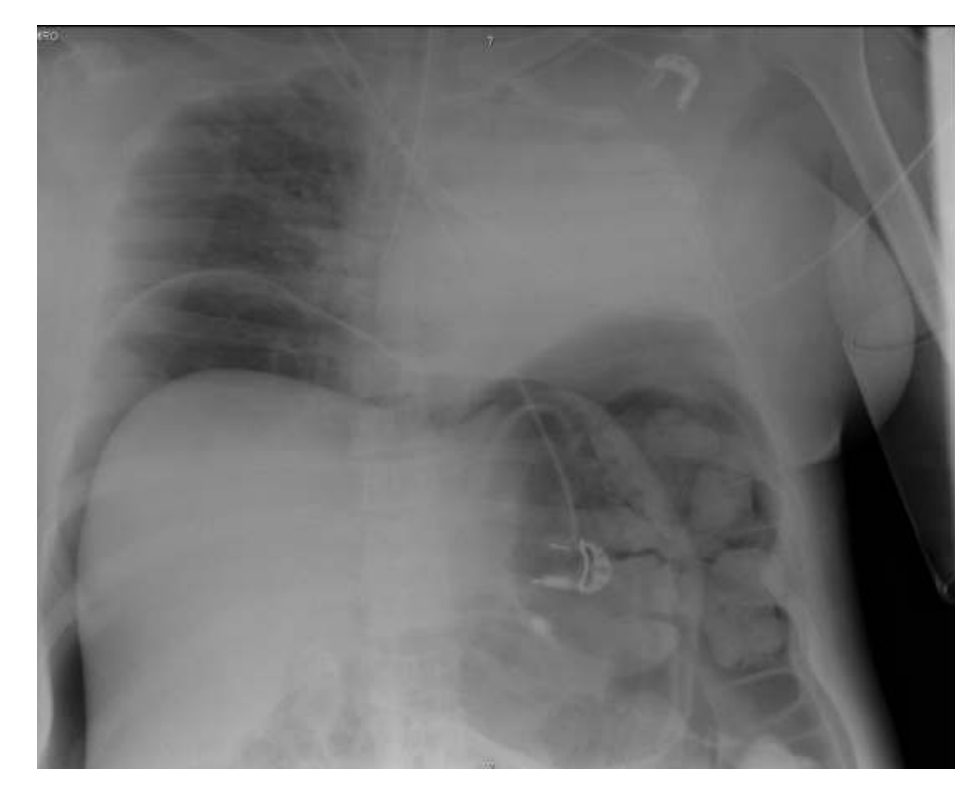

Image 2. Thoracic / abdominal x-ray showing left pulmonary atelectasis.

\section{Learning points}

$\checkmark$ Gastric rupture is a rare, but potential life-threatening complication of bag mask ventilation.

$\checkmark$ When associated with hemodynamic instability, gastric rupture requires immediate intervention.

$\checkmark$ We should always keep our standards of care even for minor procedures outside the operating room and be aware for complications occurrence.

1 - Gastric rupture following bag-valve-mask ventilation, The Journal of Emergency Medicine, Vol22, Issue 1, Jan 2002, Pages 27-29

2 - Gastric Rupture With Tension Pneumoperitoneum: A Complication of Difficult Endotracheal Intubation, Annals of Emergency Medicine, Vol30, Issue 3, Sept1997, Pages 343-34 